\title{
Autophagic Balance Between Mammals and Protozoa: A Molecular, Biochemical and Morphological Review of Apicomplexa and Trypanosomatidae Infections
}

\author{
Thabata Lopes Alberto Duque, \\ Xênia Macedo Souto, \\ Valter Viana de Andrade-Neto, \\ Vítor Ennes-Vidal and \\ Rubem Figueiredo Sadok Menna-Barreto \\ Additional information is available at the end of the chapter \\ http://dx.doi.org/10.5772/54970
}

\section{Introduction}

Protozoa are unicellular eukaryotes that are able to live as parasites or as free-living organisms and interact with a great variety of environments and organisms, from bacteria to man; in addition, they represent one of most important sources of parasitic diseases. Every year, more than one million people die from complications from protozoal infections worldwide [1-5]. Of the medically relevant protozoa, Trypanosomatidae and Apicomplexa constitute a substantial group including the causative agents of several human diseases such as Chagas disease, sleeping sickness, leishmaniasis, malaria and toxoplasmosis $[1,5,6]$. The life cycles of these parasites are highly complex, involving different hosts and different specific interactions with a variety of cells and tissues [7- 11]. Some of these parasites live in the extracellular matrix or blood of host mammals, but the majority of them infect host cells to complete their cycle. Despite the high infection and mortality rates of these protozoa, especially in low-income populations of developing regions such as Africa, Asia and the Americas, current therapies for these parasitic diseases are very limited and unsatisfactory. The development of efficient drugs is urgently necessary, as are serious public health initiatives to improve patients' quality of life [12-16]. 
The Trypanosomatidae family belongs to the order Kinetoplastida and is comprised of flagellated protists characterised by the presence of the kinetoplast, a DNA-enriched portion of the mitochondrion localised close to the flagellar pocket. The most studied pathogenic trypanosomatids are the following: (a) Trypanosoma brucei, which is responsible for sleeping sickness in Africa; (b) T. cruzi, which is the causative agent of Chagas disease in Latin America; and (c) a variety of Leishmania species that cause leishmaniasis in tropical and subtropical areas worldwide. These illnesses have been classified by the World Health Organization as neglected diseases, which affect people living in poverty in developing countries and for which no efficient therapy is available [17-19].

The Apicomplexa family encompasses a large group of protists, including approximately 5,000 known parasitic species, which are characterised by the presence of an apical complex containing a set of organelles involved in the infection process. Apicomplexan parasites infect invertebrate and vertebrate hosts, including humans and other mammals. The most serious parasitic disorder is caused by apicomplexan Plasmodium species, the etiological agent of malaria, which causes more than one million deaths annually [1]. Toxoplasmosis is another important disease caused by the apicomplexan parasite Toxoplasma gondii; it has been estimated that almost half of the human population worldwide is infected with this protozoa [20]. The life cycle of the apicomplexan parasites generally consists of complex asexual and sexual reproduction, but some differences are observable among distinct genera. Malaria transmission occurs during the blood feeding of the Anopheles mosquito, whereas toxoplasmosis is mainly transmitted by the ingestion of raw meat or contaminated cat feces.

Autophagy is a physiological self-degradative pathway essential for the maintenance of the metabolic balance in eukaryotes, leading to the turnover of cellular structures during both the normal cell cycle and during conditions of stress, such as starvation [21,22]. This process depends on double-membrane vesicles known as autophagosomes, which are responsible for the engulfment of macromolecules and organelles and the recycling of their components without an inflammatory response [23]. In eukaryotic cells, proteins known as Atgs contribute to the formation of autophagosomes and their targeting to lysosomes [24]. The autophagic machinery interfaces with many cellular pathways, such as that of the immune response and the inflammatory process, and acts as an inductor or suppressor of these processes [25]. Some molecules and organelles can undergo autophagy by specific proteins, such as in the selective pathway known as xenophagy, which is also observed in the degradation of intracellular pathogens $[26,27]$. The involvement of autophagy in this process has been demonstrated in the interactions of different pathogens with the host cells [28-30]. In protozoan infections, the role of autophagy has been debated in light of conflicting evidence presented in the literature, which tends to vary with the experimental model. Some studies suggest that parasites evade host cell defences using autophagy, while others suggest that the host uses autophagy to eliminate the pathogen [31-35]. However, there is no doubt that the autophagic machinery decisively influences the pathogenesis and virulence of protozoan infections; this machinery may therefore represent a promising target for drug discovery [36]. The autophagic process also occurs in the protozoa $[37,38]$ and could occur in parallel to the host cell pathway, thus increasing the complexity of the phenomena. In the following sub-sections, the biology of 
Trypanosomatidae and Apicomplexa protozoa will be reviewed in relation to the role of autophagy during the infection of the host cells.

\section{Trypanosomatids and autophagy}

As previously mentioned, the transmission of neglected diseases caused by trypanosomatids (sleeping sickness, Chagas disease and leishmaniasis) depends on an insect vector, and the environmental change from one host to another is a drastic event for the protozoa. To complete its life cycle, many metabolic and morphological changes must occur for the parasite to survive in a new host [39-42]. In addition to the kinetoplast, other characteristic ultrastructural structures are present in these parasites, including a single mitochondrion, unique flagella, sub-pellicular microtubules, glycosomes, acidocalcisomes and reservosomes (the last one is present exclusively in T. cruzi) [8]. In the context of the remodelling of sub-cellular structures, autophagy is greatly involved in eukaryotic homeostasis (including in that of trypanosomatids). However, the deregulation of this pathway, which is induced by conditions of stress, also leads to the parasite's death (Table 1). The sequencing of the complete genome of trypanosomatids has enabled the identification of parasitic genes [43-45]. Blast analysis comparing the trypanosome genome with yeast and mammalian genomes, with a particular emphasis on genes encoding autophagic machinery, has indicated the presence of some ATG genes in trypanosomatids $[46,47]$. However, the partial lack of a ubiquitin-like system, which is crucial for autophagosome formation, and the absence of cytoplasm-to-vacuole-targeting pathway orthologs suggest that these parasites have alternative autophagic features.

\section{T. brucei}

T. brucei is the etiological agent of sleeping sickness (or African trypanosomiasis) and is transmitted by the infected tsetse fly (Glossina sp.). After a blood feeding, procyclic trypomastigotes migrate from the insect midgut to the salivary gland where they undergo differentiation to infective metacyclic forms. Subsequently, these metacyclic trypomastigotes are inoculated into the mammalian host during the blood meal of the fly and differentiate into a proliferative bloodstream slender form. Interestingly, after a new differentiation, adapted short-stumpy forms evade the host immune system and disseminate the infection to the whole body; these forms are also able to cross the blood-brain barrier, which causes severe behavioural abnormalities, such as somnolence during daytime [48] (Figure 1). Unlike all other pathogenic trypanosomatids, which have an intracellular life-stage, T. brucei remains in the bloodstream of the mammalian host throughout the process of infection and, as such, is exposed to different environmental conditions that can trigger autophagy.

\subsection{Role of autophagy in T. brucei}

The first report on this parasite and autophagy was published in the 1970s by Vickerman and colleagues. These authors described the presence of myelin-like structures in different forms 
of the parasite observed by transmission electron microscopy $[49,50]$. Many years later, it was suggested that the autophagic pathway is involved in the turnover of glycosomes during protozoan differentiation [51]. Glycosomes are peroxysome-like organelles that perform early glycolytic steps and are also involved in lipid metabolism. It was demonstrated that glycosome contents are altered depending on the form of the parasite, with many of these organelles being close to glysosomes during the differentiation process. A similar phenomenon was observed after nutrient deprivation of the parasite, reinforcing the fact that differentiation may cause the degradation of glycosomes by pexophagy.

Further genomic and bioinformatic analyses were performed that identified in T. brucei many ATG orthologs to those of yeasts and mammals [47,52]. These genes are involved in different steps of the autophagic pathway, such as induction (ATG24, PEX14, TOR1 and TOR2, VAC8), vesicle nucleation (ATG6, VPS15 and VPS34) and vesicle expansion and completion (ATG3, ATG7, ATG9, two isoforms of ATG4 and ATG8). Two isoforms of Atg4 and two of Atg8 were recently characterised structurally [53], and it was postulated that Atg8.2 is essential for autophagosome formation and that Atg8 depletion is associated with delayed cell death [54].

It is thought that many drugs may trigger autophagy in African trypanosomes. Dihydroxyacetone (DHA), spermine (snake venom) and vasoactive intestinal peptide (VIP - a neuropeptide secreted by the immune system) induce the appearance of morphological features of autophagy in T. brucei [55-58]. DHA is an interesting compound to be used in therapy for sleeping sickness because its phosphorylation is DHA kinase-dependent, and DHA kinase is present in mammals and other eukaryotes but not in trypanosomes. After DHA uptake, this compound is not eliminated, leading to typical morphological characteristics of autophagy similar to those found in rapamycin treatment. In another report [59], the authors showed that hydrogen peroxide can produce the appearance of autophagic profiles, suggesting that the release of reactive oxygen species acts as a signal in the autophagic pathway in T. brucei, as it does in other eukaryotic cells [60-62].

\section{T. cruzi}

T. cruzi is the causative agent of Chagas disease. It is mainly transmitted by triatomine bugs, which are commonly known as "kissing bugs". In the insect midgut, proliferative forms of the parasite called epimastigotes differentiate to metacyclic trypomastigotes after migration to the posterior intestine. During the blood meal, triatomines eliminate urine and feces with infective trypomastigotes that then gain access to the vertebrate bloodstream. After internalisation in the host cell, trypomastigotes remain in parasitophorous vacuoles (PV) that fuse with lysosomes, allowing an acidification of this compartment, which is an essential step towards differentiation into proliferative amastigotes. In the cytosol, successive parasite cycles occur until a new intracellular differentiation to trypomastigotes occurs; it is these forms that are responsible for the infection and dissemination to other cells and tissues [8] (Figure 2). 


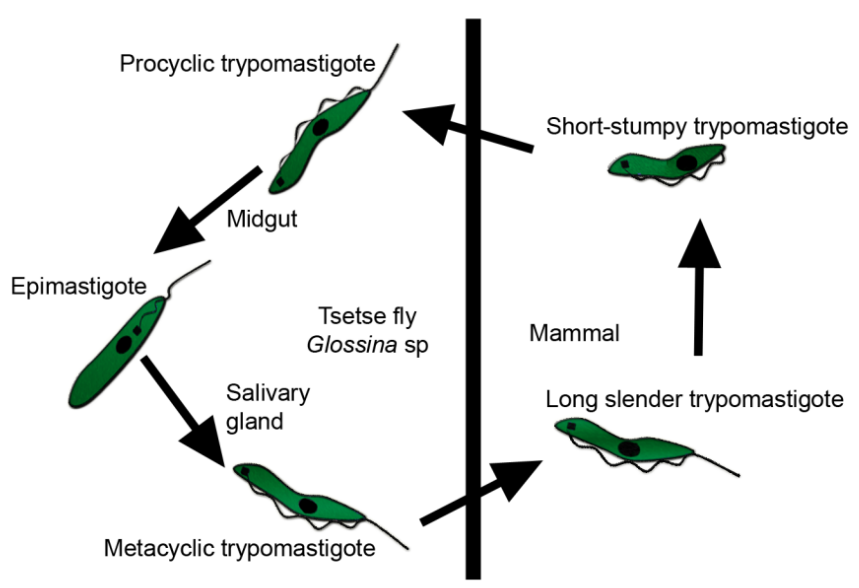

Figure 1. T. brucei life cycle.



Figure 2. T. cruzi life cycle.

\subsection{Role of autophagy in T. cruzi}

Ultrastructural evidence of autophagy in T. cruzi was observed after the treatment of epimastigotes and bloodstream trypomastigotes with drugs; the appearance of myelin-like figures was the most recurrent feature detected [63-67]. Recently, the synergistic combination of amiodarone and posoconazole was able to trigger autophagy in replicative amastigotes [68]. 
In this way, different classes of therapeutic agents are able to induce the formation of autophagosomes, an event associated with parasite-related autophagic cell death, being the interplay between other programmed cell death as apoptosis or necrosis not discarded [69]. Due to the limitations of cell models, previous studies of different parasite forms have employed alternative techniques, such as monodansylcadaverine (MDC) staining and ATG gene expression, to demonstrate autophagy in the parasite [66,67]. Unfortunately, T. cruzi molecular machinery does not allow the use of double-stranded RNA to knock down target RNAs [70]; in addition, the lack of recognition of protozoan proteins by anti-Atg commercial antibodies hampers the evaluation of autophagy in this parasite. In spite of the advances in molecular and cellular biology, transmission electron microscopy remains a gold standard for autophagy analysis [71,72].

Aside from the description of autophagosomes in all T. cruzi life stages, description of the Atg cascade involved in autophagosome formation is not complete. Almost all T. brucei ATG genes have ortholog genes in T. cruzi [37,47]. In this parasite, two isoforms of Atg8 were described, with only Atg8.1 localised in autophagosomes as expected. These data suggest that there is only partially shared autophagic machinery, as is observed in human Atg8 orthologs [37]. In another study [37], the authors described the participation of T. cruzi Atg4 and Atg8 isoforms under conditions of nutritional stress and in the differentiation process from epimastigotes to metacyclic trypomastigotes, a process known as metacyclogenesis. The authors observed a remarkable expression of Atg8.1 by immunofluorescence microscopy, which was suggestive of intense autophagy in differentiating epimastigotes. Moreover, Atg8 co-localised with reservosomes, which are pre-lysosomal compartments related to energy supply that are present only in epimastigotes [73,74]. The reservosomal content consumed during metacyclogenesis and the presence of Atg8 in this organelle strongly suggest that there is crosstalk between autophagy and reservosomes $[75,76]$. Transmission electron microscopy studies have produced images from endoplasmic reticulum profiles surrounding reservosomes that indicate the possible origin of preautophagosomal structures [66]. It is well known that PI3K inhibitors, such as 3-methyladenine and wortmannin, prevent autophagy in different experimental models [54,66]; however, these data are controversial due to a previous report demonstrating that treatment with kinase inhibitors staurosporine, genistein, 3-methyladenine and wortmannin led to the formation of autophagosomes [77]. The data indicate the necessity of careful use of PI3K inhibitors to block autophagy and the urgent need for the development of new specific autophagic inhibitors [78].

\subsection{Host cell autophagy and T. cruzi infection}

Though thought to be essential for parasite success, lysosomal fusion could be involved in autophagy during host cell interaction and might contribute to the process of degradation and elimination of T. cruzi. In 2009, the role of autophagy in parasite entry and co-localisation with the PV was described, resulting in increased infection of Chinese hamster ovary cells; this observation was subsequently confirmed in macrophage and heart cell lineages $[34,79]$. Starvation conditions and the addition of rapamycin led to an increase in the scale of the infection; this increase was partially reversed by 3-methyladenine, wortmannin and vinblas- 
tine, suggesting that autophagy favours the parasite during T. cruzi-host cell interactions. However, other groups demonstrated that classical autophagic stimuli (nutritional stress and rapamycin) did not produce an increase in parasite proliferation or even in the number of infected cells [33]. Recently, studies have emphasised role of autophagy in the control of $T$. cruzi infection using different cells and parasite strains (Figure 3) [80,81]. Once more, the conflicting data presented in the literature need to be further debated in light of the complexity of the protozoal strains and host cell models employed.

\section{Leishmania species}

The other medically important trypanosomatids are Leishmania species. Leishmaniasis is transmitted to mammals by sandflies, mainly of the Phlebotomus and Lutzomia genuses. Amastigotes differentiate into replicative procyclic promastigotes in the digestive tract of these sandflies, proliferate in the Phlebotominae gut, and then migrate to the proboscis where a new differentiation occurs to metacyclic promastigotes, the infective forms of the parasite. During the sandflies' blood meals, metacyclic promastigotes are inoculated into mammalian tissue and are phagocytised by macrophages. Inside the host cells, promastigotes differentiate into amastigotes that replicate and are responsible for cell lysis and dissemination in the organism (Figure 4). Currently, more than 20 species of Leishmania are known, each causing different clinical manifestations of the disease, including cutaneous leishmaniasis and visceral leishmaniasis (or Kala-azar). The pathogenicity depends on the Leishmania species and the host's immune response [8].

\subsection{Role of autophagy in Leishmania sp.}

Many groups have investigated autophagy cell death induced by drugs or antimicrobial peptides in various Leishmania species using electron microscopy and MDC staining [82-89]. Bioinformatics analysis has been a crucial checkpoint in the characterisation of ATG and TOR pathways in trypanosomatids $[38,47,90]$. In 2006, the role of autophagy in the differentiation process of L. major and L. mexicana was first evaluated $[38,90]$. The authors developed $L$. major VPS4, a mutant that could not complete the differentiation to the infective forms due to interference in autophagosome formation during conditions of starvation. The increase in Atg8 expression in differentiating forms supports the hypothesis that autophagy plays a pivotal role in metacyclogenesis [38,91]. In L. mexicana, the lack of cysteine peptidases CPA and CPB impairs autophagosomes formation and parasite differentiation; this finding is corroborated by the results of wortmaninn treatment and ATG deletion [90].

Recently, a subunit of protein kinase A in L. donovani that interferes with autophagy and protozoa differentiation was identified [92]. As observed in other trypanosomatids, the presence of Atg8-like proteins and their association with Atg4 in Leishmania species indicates that these proteins play a role in vesicle expansion [93]. Interestingly, the Atg5-Atg12 complex involved in autophagosome elongation was not previously detected [47], but recent studies have demonstrated its existence. It has also been shown that Atg5 deletion severally affects 


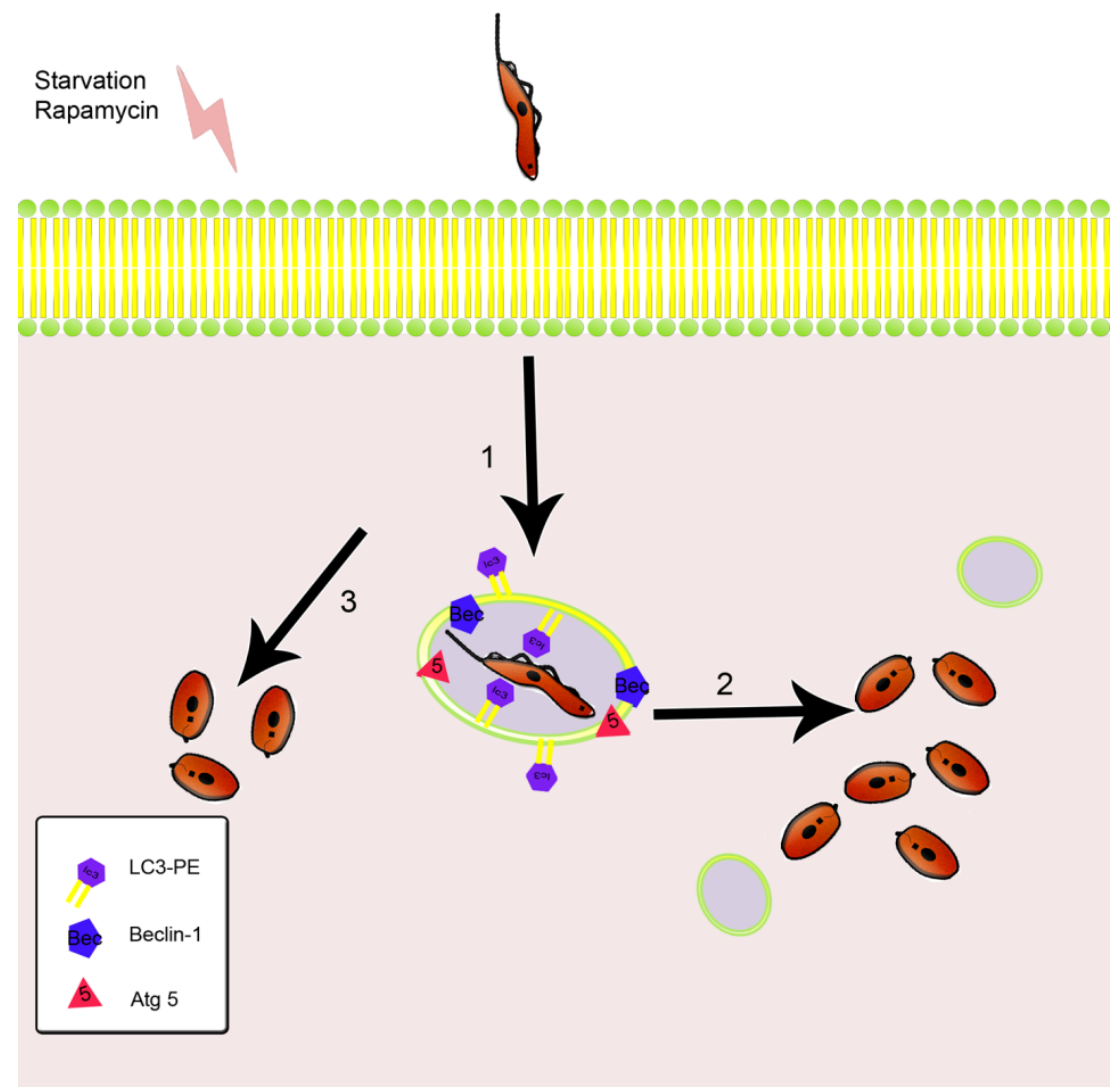

Figure 3. Autophagy in T.cruzi-host cell interaction. Romano et al [34] showed the co-localization of parasite vacuole with Atg proteins in the beginning of infection (1). Moreover, the replication of amastigotes is the same with or without autophagy induction (2) [33,34]. Rapamycin and starvation control infection reducing the number of amastigotes per cell (3) [80,81].

parasite homeostasis, producing a phenotype characterised by mitochondrial disruption, phospolipid accumulation and abnormal promastigote morphology [93,94]. Table 1 summarises the autophagic events in the three pathogenic trypanosomatids described in this chapter.

\subsection{Host cell autophagy and L. amazonensis infection}

The connection between the endosomal/lysosomal pathway and the PV results in macromolecules being taken up by the parasite, as demonstrated in T. cruzi infection [96]. In this context, a notable increase in the proliferation of L. amazonensis amastigotes was observed after autophagic induction by nutritional deprivation, rapamycin treatment or interferon-gamma. This mechanism was partially reversed by the autophagic inhibitors wortmaninn or 3methyladenine, which significantly reduced amastigote replication (Figure 5) [33]. However, 


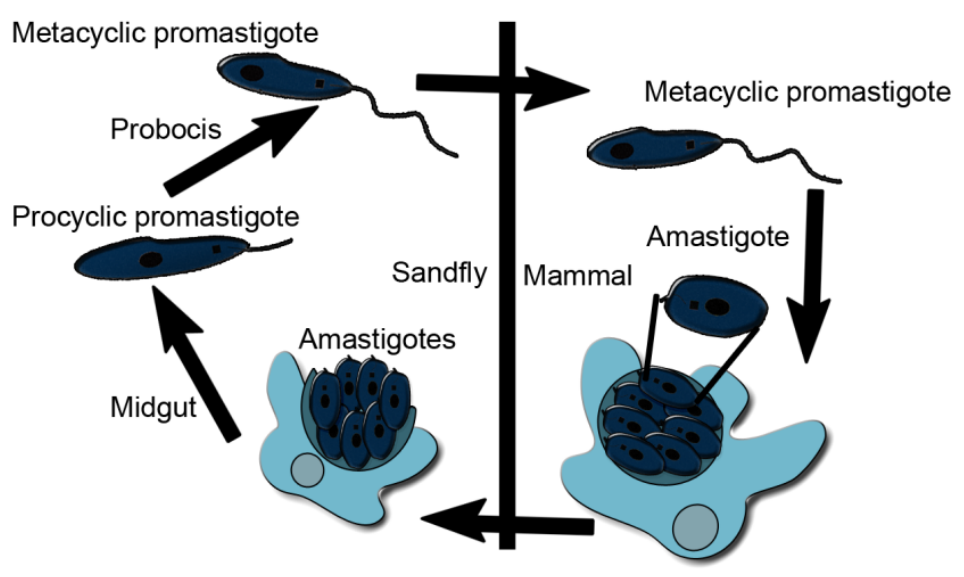

Figure 4. Leishmania sp. life cycle.

a recent report presented no correlation between the increase in LC3 expression and heightened L. amazonensis infection after treatment with autophagy inducers and inhibitors. In addition, macrophage autophagy was observed in inflammatory infiltrates of L. amazonensisinfected mice [97] and in natural human L. donovani infection [98].

\section{Apicomplexa and autophagy}

The phylum Apicomplexa comprises one of the most medically relevant groups of protists, which cause serious health and economic problems. Among these parasites, Toxoplasma gondii and Plasmodium species are well-known apicomplexans; it is estimated that malaria caused by P. falciparum kills over a million people annually. Another widespread disease is toxoplasmosis, which is caused by the apicomplexan parasite T. gondii; the severity of disease caused by this organism is directly related to patients' immunosuppression and is characterised by congenital transmission. In this context, knowledge of the detailed mechanisms involved in parasite infection and survival, including the role of autophagy, could contribute important information to the development of novel strategies for controlling Apicomplexa infections. Autophagy is an evolutionarily conserved pathway found in all eukaryotes, from unicellular organisms to metazoans; orthologs for approximately $30 \%$ of autophagy-related genes have been detected in apicomplexan sequenced genomes [99].

Among the key molecules involved in early autophagy steps, Atg1/ULK complex, Atg8 and Atg9 play crucial roles in cargo selectivity and in autophagosome formation [100,101]. Unlike other cell models, in Apicomplexa protozoa, the Atg8 C-terminal appears to not undergo processing before its association with phosphatidylethanolamine (PE) in the membrane of 


\begin{tabular}{|c|c|c|c|c|}
\hline Parasite & Life-stage & Phenotype & Stimuli & References \\
\hline \multirow{4}{*}{ T. brucei } & $\begin{array}{l}\text { bloodstream } \\
\text { trypomastigotes }\end{array}$ & autophagic cell death & $\begin{array}{l}\text { DHA, neuropeptides, } \\
\text { rapamycin, starvation }\end{array}$ & {$[55,58,59]$} \\
\hline & \multirow{3}{*}{$\begin{array}{c}\text { procyclic } \\
\text { trypomastigotes }\end{array}$} & autophagic cell death & spermine (snake venom) & [57] \\
\hline & & $\begin{array}{l}\text { Autophagy-induced } \\
\text { differentiation }\end{array}$ & rapamycin, starvation & {$[54,56]$} \\
\hline & & $\begin{array}{l}\text { unfolded protein response } \\
\text { in endoplasmic reticulum } \\
\text { associate with autophagy }\end{array}$ & DTT & [95] \\
\hline \multirow[t]{2}{*}{ T. cruzi } & $\begin{array}{l}\text { epimastigotes, } \\
\text { trypomastigotes }\end{array}$ & autophagic cell death & $\begin{array}{l}\text { SBIs; LPAs and cetoconazole; } \\
\text { naphthoquinones; } \\
\text { naphthoimidazoles; MBHA; } \\
\text { posoconazole and } \\
\text { amiodarone }\end{array}$ & $\begin{array}{l}{[63-65,67,} \\
68,71,72,]\end{array}$ \\
\hline & $\begin{array}{c}\text { metacyclic } \\
\text { trypomastigotes }\end{array}$ & $\begin{array}{l}\text { Autophagy-induced } \\
\text { differentiation }\end{array}$ & $\begin{array}{l}\text { starvation; differentiation } \\
\text { medium }\end{array}$ & [37] \\
\hline L. amazonensis & $\begin{array}{l}\text { promastigotes, } \\
\text { amastigotes }\end{array}$ & autophagic cell death & $\begin{array}{c}\text { amiodarone; elatol; lipophilic } \\
\text { diamine }\end{array}$ & {$[83,86,89]$} \\
\hline L. chagasi & promastigotes & autophagic cell death & yangambin & [87] \\
\hline L. donovani & promastigotes & autophagic cell death & $\begin{array}{l}\text { antimicrobial peptides; } \\
\text { cryptolepine }\end{array}$ & {$[82,88]$} \\
\hline \multirow{2}{*}{ L. major } & $\begin{array}{l}\text { promastigotes, } \\
\text { amastigotes }\end{array}$ & autophagic cell death & cathepsin inhibitors & [85] \\
\hline & $\begin{array}{c}\text { metacyclic } \\
\text { promastigotes }\end{array}$ & $\begin{array}{l}\text { autophagy induces } \\
\text { differentiation }\end{array}$ & $\begin{array}{l}\text { differentiation medium; } \\
\text { starvation }\end{array}$ & {$[38,91]$} \\
\hline L. donovani & $\begin{array}{c}\text { metacyclic } \\
\text { promastigotes }\end{array}$ & $\begin{array}{l}\text { autophagy induces } \\
\text { differentiation }\end{array}$ & $\begin{array}{l}\text { differentiation medium; } \\
\text { starvation }\end{array}$ & [90] \\
\hline
\end{tabular}

Table 1. Summary of autophagic events in trypanosomatids. DHA: Dihydroxyacetone; DTT: dithiothretiol; SBIs: sterol biosynthesis inhibitors; LPAs: Iysophospholipid analogues; MBHA: Morita-Baylis-Hillman adduct.

autophagosomes, suggesting a different regulation of this Atg protein in these organisms than in mammals and fungi [102]. Using a technique to detect lipidated Atg8 in Plasmodium species, only a single band corresponding to ATG8 was observed, suggesting that this parasite's Atg8 exists predominantly in the PE-conjugated form [22].

Two important kinases have opposing roles in the autophagic process: TOR (target of rapamycin) and class III phosphatidylinositol3-kinase (PI3K) [78,103]. In well-established autophagic models, TOR and class III PI3K represent negative and positive regulators, respectively, that act through complexes with regulatory subunits orchestrated by signalling cascades. 


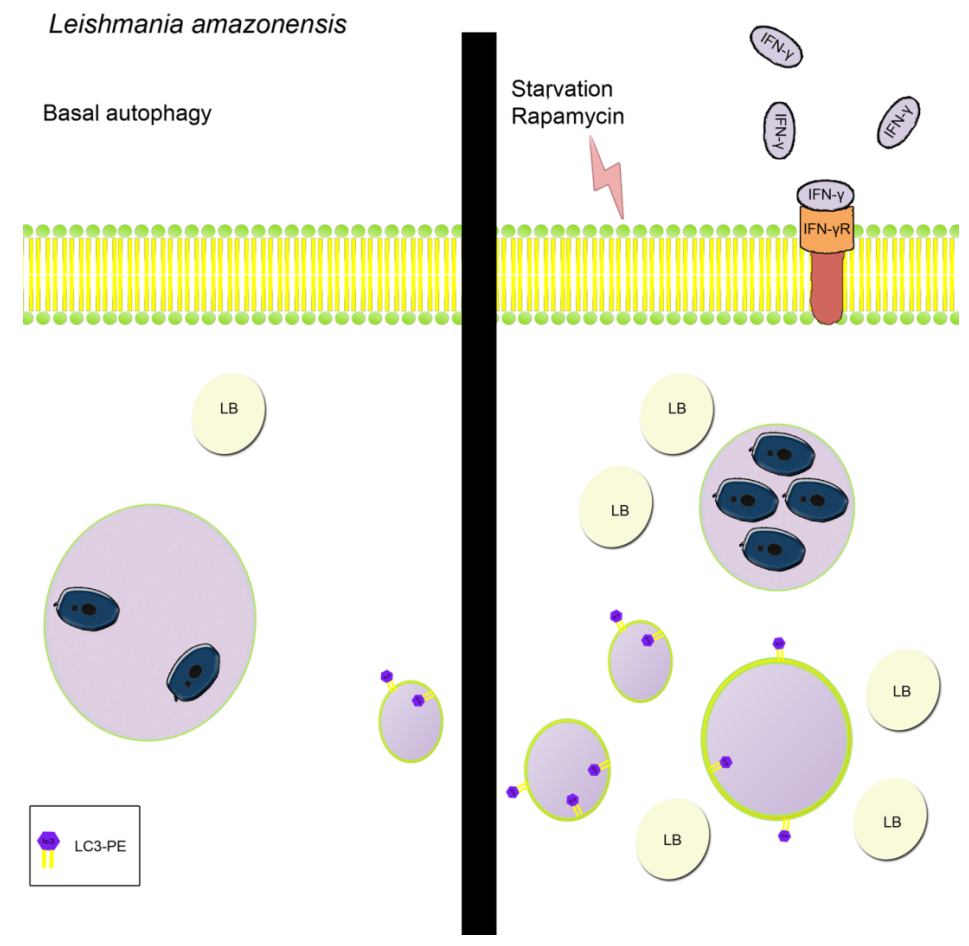

Figure 5. Autophagy in L. amazonensis-host cell interaction. When autophagy is induced, more amastigotes replicate and PV is smaller than in basal autophagic cells. Also, more lipid bodies are present, increasing infection and signaling to replication $[33,97]$.

Analysis of the T. gondii genome revealed the presence of TOR and PI3K but not of other proteins crucial to the formation of these complexes [99]. Curiously, no genes for TOR complex machinery were found in the Plasmodium genome. Thus, it is possible that these unicellular eukaryotes have specific unknown proteins for several steps of the autophagic pathway instead of an absence of key proteins [22,104].

\section{T. gondii}

T. gondii is an obligate intracellular parasite with a complex life cycle involving one definitive feline host where the sexual phase occurs and intermediate hosts, such as birds, other mammals and man [105]. The main transmission routes to humans are the following: (i) the ingestion of raw meat containing tissue cysts (essentially bradyzoites forms); (ii) the ingestion of water and food contaminated with feline feces residue containing oocysts; and (iii) transplacentary pathway of tachyzoites [106]. After oral ingestion, tissue cysts or oocysts rupture, liberating the slow-replicating forms known as bradyzoites and sporozoites, respectively, which then 
invade intestinal epithelial cells. In the intracellular environment, the parasites differentiate into the fast-replicating tachyzoites that proliferate inside the host cell PV. The sustained infection depends on the modification of the PV membrane by the insertion of T. gondii secreted proteins, which prevent the fusion to lysosomes and, consequently, the elimination of the parasite (Figure 6) [20,107].

In healthy adults, T. gondii cysts are established in the host cells mainly in the eyes, brain and muscles during the chronic phase of toxoplasmosis [108]; however, in immunocompromised patients, such as HIV-positive patients, or in congenital toxoplasmosis, the disease becomes much more severe, and its complications could lead to death $[20,109,110]$. Despite the high percentage of people infected, the available therapy for toxoplasmosis is effective only in the tachyzoite stage and presents limited efficacy against the tissue cyst, which is the latent form of the parasite [111]. In this context, many efforts are necessary to develop new drugs to treat T. gondii infection [17].

\subsection{Role of autophagy in T. gondii infection}

Only a few studies on the T. gondii autophagic pathway have been performed, and these studies suggest opposing roles of autophagy in the parasite infection [102,112]. The presence of TgAtg8 in autophagic vesicles was observed in tachyzoites during their intracellular replication; similarly, severe parasite growth arrest due to TgAtg3 knockdown and recent identifications of the presence of TgAtg1 and TgAtg4 in the parasite suggest a role for autophagy in $T$. gondii homeostasis, although long-term exposure to autophagic stimuli was found to be harmful to the parasite (Figure 7) [112; 113].

Tachyzoites divide by a process called endodyogeny, whereby two daughter cells are developed inside a mother cell and leave residual material at the end of division. During this process, autophagy might be involved in recycling the mother cell organelles, such as micronemes and rhoptries, which are synthesised de novo in the daughter cells; however the accumulation of organelles after endodyogeny has not been observed in TgATG3 knockout organisms, making other experiments necessary to confirm this hypothesis [113]. One important phenotype detected in autophagic mutants is the loss of mitochondrial integrity [102,112]. Mitophagy, which is the autophagy of mitochondria, regulates the mitochondrial number to match metabolic demand; this process represents a quality control that is necessary for the removal of damaged organelles [114]. Autophagic stimuli are able to direct the mitochondrial network of tachyzoites towards their autophagic pathway, but the molecular machinery involved in selective targeting of the organelle remains unclear [102,112]. Nutrient deprivation has been shown to be a classic stimulus for the autophagic pathway activation in a large variety of organisms $[37,115]$. In T. gondii tachyzoites, starvation induces autophagy in extracellular and intracellular parasites [102,112]. Furthermore, autophagosomes were observed in parasites after a long extracellular nutritional restriction, suggesting that autophagy can act as a mechanism of resistance to starvation for nutrient recycling until the infection of a new host cell [102]. 


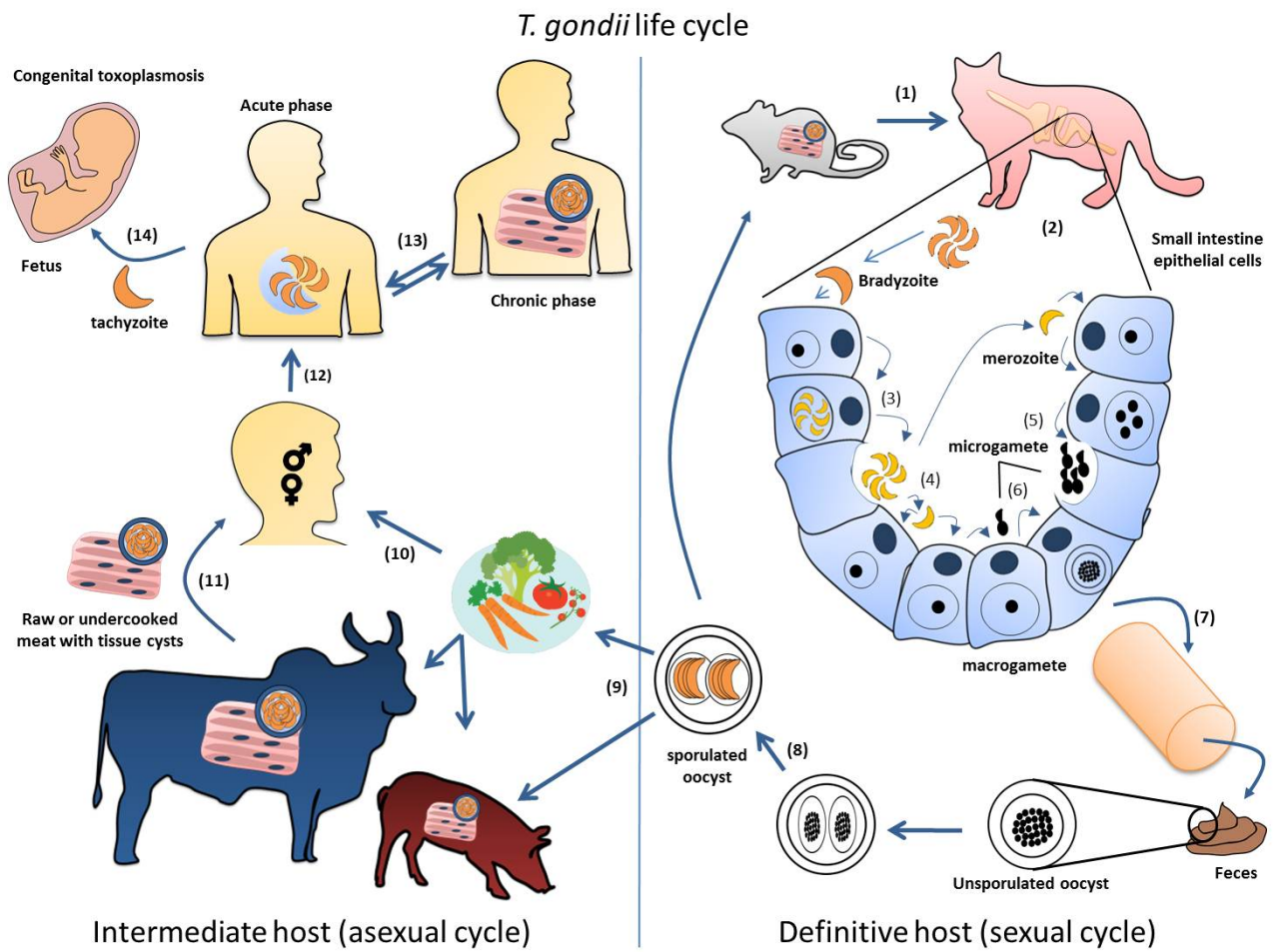

Figure 6. T. gondii life cycle. (1) Definitive host infection; (2) Cyst disruption and intestinal epithelial cell infection; (3) Formation of merozoites; $(4,5)$ Start of sexual phase with the formation of macrogametes and flagellate microgametes from merozoites; (6) Fusion of microgamete and macrogamete; (7) Oocyst release to the environment in the faeces; (8) The unsporulated oocysts become infective and contaminate the environment [116-118]; (9) The sporulated oocysts can cause infection of animals via consumption of contaminated food and water. $(10,11)$ Human infection occurs by the ingestion of raw or undercooked meat of infected animals containing T. gondii cysts; (12) T. gondii tachyzoite multiplication in the intermediate host; (13) Tachyzoite-bradyzoite differentiation and formation of tissue cysts; (14) Transplacentary transmission of tachyzoites.

The data presented here demonstrate possible functions of T. gondii autophagy in parasite homeostasis. However, it has been proposed that, when strongly induced, the autophagic pathway represents a self-destructive mechanism leading to protozoal death. The molecular pathway of autophagic cell death is still unknown, and it is debated whether the pathway is a type of programmed cell death or a survival response to death stimuli [119]. Intracellular starved tachyzoites showed systematic mitochondrial fragmentation and a defect in host cell internalisation. As T. gondii is an obligate intracellular protozoa, the loss of invasion capacity leads to parasite death. The impairment in infective ability was related to the loss of mitochondrial integrity because organelles from apical complexes, such as rhoptries and micronemes, which are usually associated with the invasion process, are intact in these parasites [112]. Interestingly, these authors also demonstrated that autophagic inhibitor 3-methylade- 


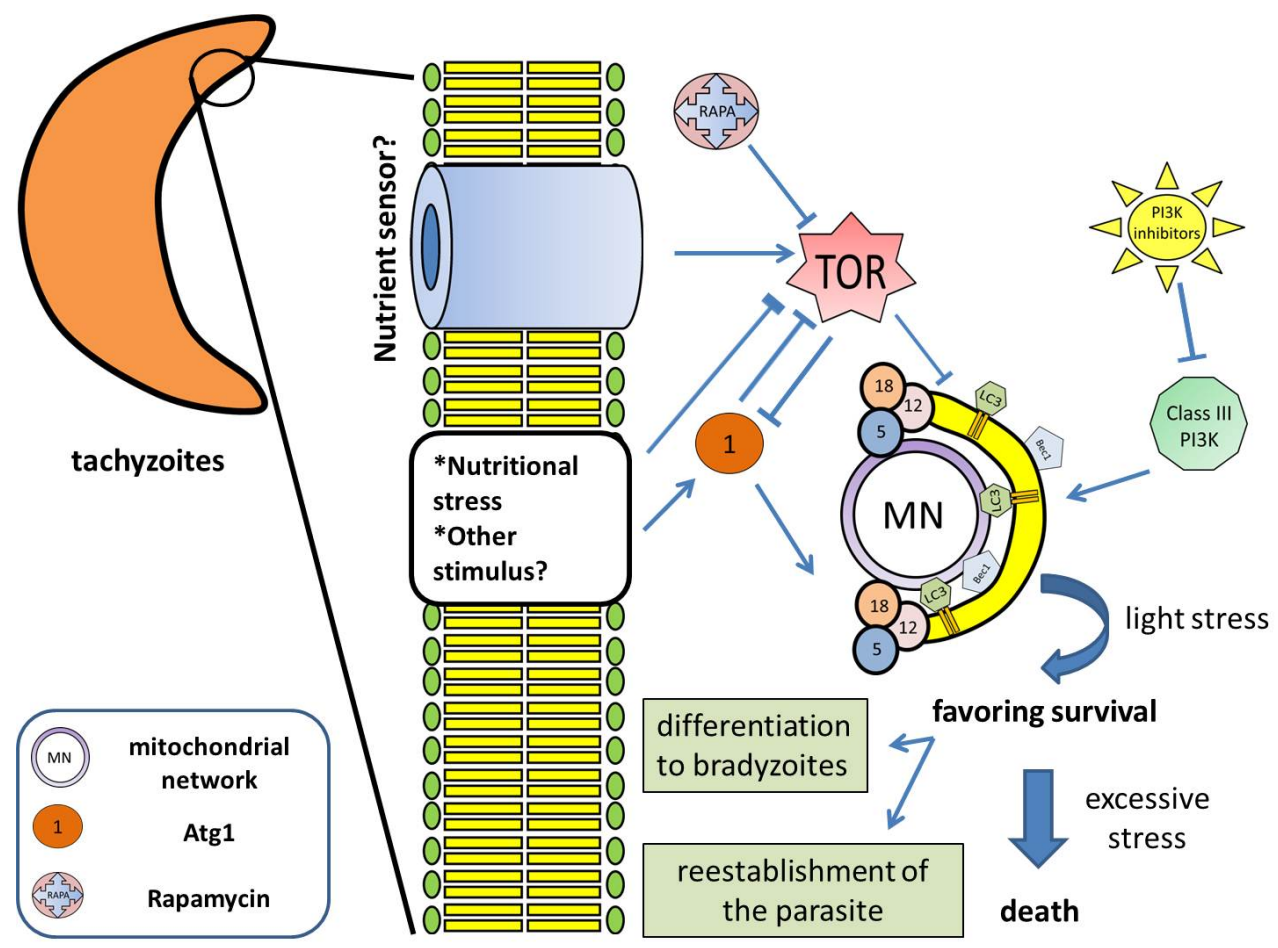

Figure 7. T. gondii tachyzoites response to autophagic stress. Autophagy acts in survival or death mechanisms in apicomplexan parasites depending on the environmental stress conditions. Arrows: activation; Headless arrows: inhibition.

nine prevented mitochondrial fragmentation, suggesting autophagic involvement in $T$. gondii death.

While nutritional stress has been extensively used as a model for autophagy, this condition is not easily encountered in the host cells and tissues in vivo. However, parasites could be exposed to nutritional restriction in the extracellular environment. The viability of tachyzoites kept in an axenic medium for periods of up to 12 hours drastically decreases, but a significant number of parasites nevertheless differentiate into bradyzoites [120]. Indeed, these observations raise the hypothesis that autophagy could be an adaptive mechanism of $T$. gondii to survive for short periods in starvation conditions, allowing the parasite to recover when favourable conditions occur or even to differentiate into a cystic form. Another interesting point for discussion is the correlation between mitochondrial fragmentation in intracellular tachyzoites and the depletion of amino acids in the culture medium [112]. Activated macrophages infected with the parasite showed low availability of the essential amino acid tryptophan, a condition that directly contributes to the protozoa's death in these cells [121,122]. In this context, TOR kinase is a vital component of the amino acid sensing mechanism in eukaryotic cells, as suggested by 
the detection of TgTOR by bioinformatic approaches and the evaluation of the activity of the classical TOR inhibitor rapamycin. This inhibitor triggered mitochondrial fragmentation of intracellular tachyzoites in starved parasites, and this phenotype was reversed by adding 3methyladenine [112].

\subsection{Host cell autophagy and T. gondii infection}

As previously mentioned, T. gondii can infect any nucleated cell, but the parasite tropism principally involves nervous and muscular cells where the establishment of cystic forms is observed in chronic toxoplasmosis [111,123]. As was observed for T. cruzi-host cell interactions, controversial data on the importance of autophagy during $T$. gondii infection have been described in the literature; indeed, it has been suggested that autophagy can either control or facilitate parasite internalisation and proliferation [32,35,124-128]. Despite the relevance of muscular and nervous cells for the establishment of infection and for the course of the disease, very little has been reported on the role of autophagy in the progression of infection. As we will discuss in the next paragraphs, previous studies on the connection between the autophagic pathway and T. gondii infection were performed in macrophages, which are cells that play an important role in the immune response against this parasite [129].

Previous reports have shown that cellular immunity mediated by CD40 stimulation redirects the T. gondii to a lysosomal compartment via the autophagic route, resulting in the antimicrobial activity of the macrophage in vitro and in vivo [124,125]. In vivo, parasite elimination was dependent on GTPase p-47, IFN- $\gamma$, IGTP, and PI3K and culminated in the rupture of the parasite's membrane [125] (Figure 8). Additionally, the relationship between autophagy and the fusion of lysosomes with the T. gondii PV seems to be dependent on the synergy between TRAF6 signalling downstream of CD40 and TNF- $\alpha$ [126]. However, the IFN- $\gamma / \mathrm{p} 47$ GTPasedependent elimination of the parasite by macrophages is independent of CD40/TNF signalling in vitro, demonstrating the primary role of IFN- $\gamma$ in immunity against $T$. gondii in mice [127]. As observed in astrocytes, autophagy is activated to eliminate intracellular parasite debris and thus prevent the host cell death. Investigations in macrophages also indicated that the CD40p21-Beclin 1 pathway is a CD40-dependent immunity route to mediating in vivo protection [128]. Similarly, Atg5 is required for damage to the PV membrane and removal of the parasite in primary macrophages stimulated by IFN- $\gamma$, despite the fact that no autophagosomes involving T. gondii have been detected. Atg5 also appeared crucial for in vivo p47 GTPase IIGP1 recruitment to the vacuole membrane induced by IFN- $\gamma$, suggesting an additional autophagyindependent role for Atg5 in the GTPase trafficking process [32]. In T. gondii infected astrocytes, the participation of autophagy has been shown to be indirect. The IFN- $\gamma$-stimulation of astrocytes infected with tachyzoites triggers the recruitment of p47 GTPases to the PV and usually leads to rupture of the vacuole and parasite membrane. In this case, autophagy acts by removing protozoal debris that accumulates in the cytoplasm and causes cell injury. Additionally, autophagy assists in antigen presentation through MHC class II in astrocytes, allowing an intracerebral immune response to parasite [130].

So far, little has been described regarding the involvement of autophagy in the interaction of T. gondii with nonprofessional phagocytes. In primary fibroblasts or Hela cells, infection with 
tachyzoites induced LC3 conjugation to PE, accumulation of LC3-containing vesicles close to the PV and an overexpression of beclin-1 and phosphatidylinositol-3-phosphate in the host cells in the mTOR-independent pathway. The infection of Atg5-deficient fibroblasts was reduced in physiological concentrations of amino acids, reinforcing the host cell autophagic role in the recovery of nutrients by the parasite. Because the classical function of autophagy involves recycling of various cellular components and because T. gondii depends on the uptake of many nutrients from the host cell, it has been proposed that the parasite may take advantage of the mammalian autophagic machinery to achieve successful infection [35]. Table 2 shows the host autophagic roles during T. gondii infection.



Figure 8. Autophagic role in T. gondii interaction with professional phagocytic cells. (a) INF-Y recruits P47GTPases to the PV membrane and induce nitric oxide production which limits the parasite replication. (b) CD40L activates Atg5 and recruits the autophagic machinery to the PV membrane. (c) PV and parasite membrane degradation by P47GTPase and Atg5. (d) Elimination of T. gondii debris by autophagolysosomal fusion and possible contribution of this process in antigen presentation through class II MHC. 


\begin{tabular}{|c|c|c|c|}
\hline Host cell & Induction & Phenotype & Reference \\
\hline $\begin{array}{l}\text { Peritoneal Macrophages } \\
\text { and RAW264.7 lineage }\end{array}$ & $\begin{array}{l}\text { CD40 stimulation and } \\
\text { rapamycin }\end{array}$ & $\begin{array}{l}\text { accumulation of LC3 around PV and low parasite } \\
\qquad \text { load }\end{array}$ & [124] \\
\hline Peritoneal macrophages & INF- $\gamma$ stimulation & $\begin{array}{l}\text { autophagy- dependent elimination of } \\
\text { intracellular parasite debris }\end{array}$ & [125] \\
\hline Peritoneal macrophages & INF- $\gamma$ stimulation & Atg5-dependent PV membrane disruption & [32] \\
\hline $\begin{array}{l}\text { bone marrow } \\
\text { Macrophages }\end{array}$ & $\begin{array}{l}\text { CD40-p21-Beclin } 1 \\
\text { pathway }\end{array}$ & $\begin{array}{l}\text { stimulation of autophagy for protection against } \\
\text { T. gondii }\end{array}$ & [128] \\
\hline astrocytes & INF- $\gamma$ stimulation & $\begin{array}{c}\text { T. gondii debris removal by autophagy after } \\
\text { vacuole and parasite membrane rupture by p47 } \\
\text { GTPases }\end{array}$ & [130] \\
\hline $\begin{array}{l}\text { primary fibroblasts and } \\
\text { Hela cells }\end{array}$ & T. gondii infection & $\begin{array}{l}\text { Induction of LC3 conjugation to PE, accumulation } \\
\text { of vesicles containing LC3 close to PV, beclin-1 } \\
\text { and PI3K inside the cell }\end{array}$ & [35] \\
\hline
\end{tabular}

Table 2. Autophagy in T. gondii-host cell interactions

\section{Plasmodium sp.}

Plasmodium species are causative agents of malaria, the illness with the highest morbidity rate among human parasitic diseases. Currently, 5 species of Plasmodium sp. (P. falciparum, $P$. vivax, P. malariae, P. ovale and P. knowlesi) can infect humans, and lethality is associated with P. falciparum [131-133]. Sporozoites are transmitted by Anopheles sp. mosquitoes (definitive hosts) to the mammals (intermediate hosts), where they migrate primarily to the liver. After internalisation in hepatocytes, the parasites convert from elongated sporozoites (invasion competent and motile) to round proliferative trophozoites (metabolically active), which start the asexual reproduction process known as schizogony. At the end of the reproductive process, the daughter cells (merozoites) initiate maturation for erythrocyte invasion. When the merozoites become mature, they are enclosed in a membrane (the merosome) and released from hepatocytes to invade red blood cells, causing clinical symptoms of malaria (Figure 9). [135-137].

\subsection{Role of autophagy in Plasmodium sp. infection}

Recent publications have suggested that autophagy is involved in the differentiation of sporozoites to merosomes in hepatocytes $[137,138]$. The sporozoite-to-trophozoite differentiation is accompanied by the elimination of organelles unnecessary for schizogony and the production of merozoites in liver cells [137]. For example, micronemes and rhoptries are compartmentalised in the cytoplasm of sporozoites and sequestered in double-membrane structures resembling autophagosomes. In axenic conditions, the treatment of parasites with 3-methyladenine resulted in significant delay of the sporozoite differentiation process [139]. 


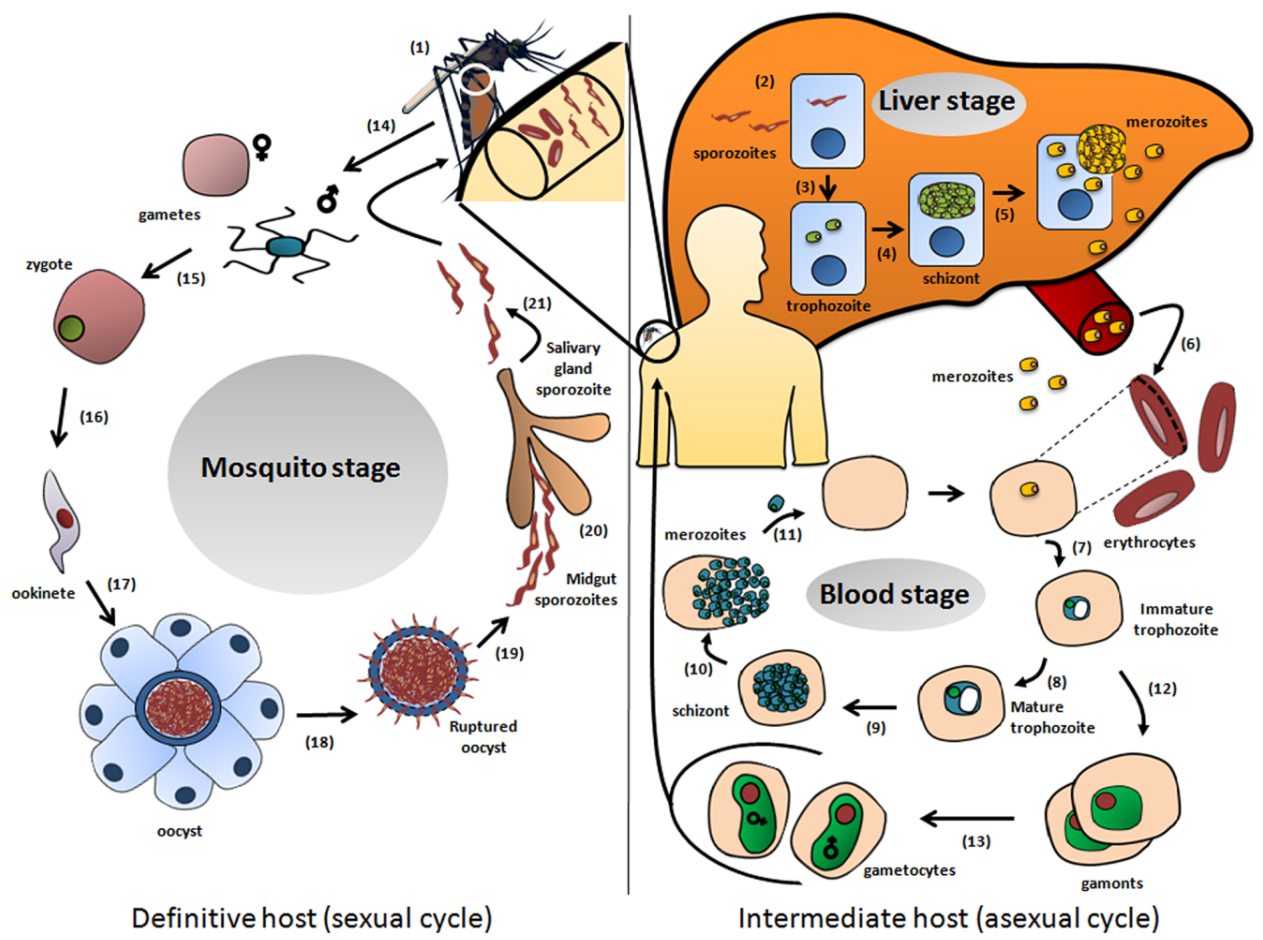

Figure 9. Plasmodium sp. life cycle. (1) Inoculation of sporozoites by malaria-infected female Anopheles mosquito into the human host. (2) Sporozoites infect hepatocytes. (3) Sporozoite-trophozoite differentiation. (4) Schizont formation. (5) Schizont rupture and release of merozoites. (6) Merozoites infect red blood cells. $(7,8)$ Trophozoite maturation. (9) Schizont formation in red blood cells. (10) Schizont rupture and release of merozoites. (11) Infection of new red blood cells by the merozoites. $(12,13)$ Differentiation of some parasites in gametocytes (sexual erythrocytic stages). (14) Ingestion of gametocytes by the mosquito during a blood meal. (15) Zygote formation in the mosquito's stomach when the microgametes penetrate the macrogametes. (16) Zygote-ookinete differentiation. (17) Ookinetes invade the midgut wall of the mosquito where they develop into oocysts. $(18,19)$ Oocysts rupture and release sporozoites. $(20)$ Sporozoites migrate to the mosquito's salivary glands. (21) Mosquito inoculates sporozoites into a new human, perpetuating the parasite cycle.

After sporozoite differentiation, Atg8 is present in autophagosomes during the replication phase, suggesting an additional independent role for this protein in autophagy $[137,138,140]$.

The involvement of autophagy in Plasmodium-infected red blood cells has been poorly studied. One study demonstrated that erythrocytes infected with P. falciparum trophozoites and maintained in supplemented culture medium expressed Atg8 in the parasite cytosol. However, when these infected cells are submitted to restriction of glucose and amino acids, an increase in the number of autophagosomes labelled by Atg8 was observed, and these vesicles were found close to red blood cell membranes. Once erythrocytes no longer have organelles in the cytoplasm, the potential targets of autophagosomes in this cell model are debated. One hypothesis suggested that these autophagosomes target haemoglobin and blood nutrients to 
favour nutrient uptake by the parasite (Gaviria and colleagues, unpublished results). Surprisingly, no TOR ortholog was found in the P. falciparum genome (Sinai \& Roepe, unpublished results), suggesting that under normal growth conditions, $P$. falciparum autophagy is configured as a survival process that is constitutively regulated by the acquisition of nutrients, although this route is unusual. Table 3 summarises the published reports on autophagic features in apicomplexans.

Little is known about the involvement of autophagy in the Plasmodium sp.-host cell interactions. So far, Plasmodium ATG8 knock-out resulted in a lethal phenotype, indicating that this gene is essential for the mammalian life-stage of the parasite [22]. However, there have been no studies on the importance of the host cell autophagic machinery during the infection.

\begin{tabular}{|c|c|c|c|c|}
\hline Parasite & Localisation & Induction & Phenotype & Reference \\
\hline \multirow{3}{*}{ T. gondii } & extracellular & Amino acid starvation & Basal: maintenance of life & [102] \\
\hline & \multirow{2}{*}{ intracellular } & $\begin{array}{l}\text { Amino acid starvation and } \\
\text { rapamycin }\end{array}$ & $\begin{array}{l}\text { mitochondrial } \\
\text { fragmentation }\end{array}$ & \multirow{2}{*}[111]{} \\
\hline & & $\begin{array}{c}\text { Glucose and/or pyruvate } \\
\text { starvation }\end{array}$ & $\begin{array}{l}\text { Arrested mitochondrial } \\
\text { fragmentation }\end{array}$ & \\
\hline Plasmodium sp. & intracellular & $\begin{array}{l}\text { sporozoite to trophozoite } \\
\text { conversion in the liver }\end{array}$ & $\begin{array}{l}\text { recycling of secretory } \\
\text { organelles }\end{array}$ & [136] \\
\hline
\end{tabular}

Table 3. Autophagy in Apicomplexan parasites

\section{Conclusion}

The present chapter addresses the positive and negative regulations of the autophagic process of infected mammalian cells and the possible effects of these regulations on the in vitro and in vivo modulation of this process. This review also describes the autophagy pathway in pathogenic trypanosomatids and apicomplexans responsible for some of the most relevant neglected illnesses worldwide. The pivotal role of autophagy in pathogenicity and virulence was demonstrated in T. cruzi, T. brucei, Leishmania sp., T. gondii and Plasmodium sp., which suggests that autophagic machinery is a possible target for anti-parasitic intervention.

\section{Acknowledgements}

This work was supported with grants from CNPq (Universal), FAPERJ (APQ1) and IOC/ FIOCRUZ. 


\section{Author details}

Thabata Lopes Alberto Duque ${ }^{1,2}$, Xênia Macedo Souto ${ }^{1,3}$, Valter Viana de Andrade-Neto ${ }^{4}$, Vítor Ennes-Vidal ${ }^{5}$ and Rubem Figueiredo Sadok Menna-Barreto ${ }^{1 *}$

*Address all correspondence to: rubemb@ioc.fiocruz.br

1 Laboratory of Cell Biology, Oswaldo Cruz Institute, Oswaldo Cruz Foundation, Rio de Janeiro, RJ, Brazil

2 Laboratory of Cell Biology, Department of Biology, Federal University of Juiz de Fora, MG, Brazil

3 Laboratory of Structural Biology, Oswaldo Cruz Institute, Oswaldo Cruz Foundation, Rio de Janeiro, RJ, Brazil

4 Laboratory of Biochemistry of Trypanosomatids, Oswaldo Cruz Institute, Oswaldo Cruz Foundation, Rio de Janeiro, RJ, Brazil

5 Laboratory of Molecular Biology and Endemic Diseases, Oswaldo Cruz Institute, Oswaldo Cruz Foundation, Rio de Janeiro, RJ, Brazil

Thabata Lopes Alberto Duque and Xênia Macedo Souto equally contributed to this work

\section{References}

[1] Nayyar GML, Breman JG, Newton PN, Herrington J. Poor-quality antimalarial drugs in southeast Asia and sub-Saharan Africa. Lancet Infectious Diseases 2012;12(6): 488-96.

[2] Soeiro MN, De Castro SL. Trypanosoma cruzi targets for new chemotherapeutic approaches. Expert Opinion on Therapeutic Targets 2009;13(1):105-21.

[3] Kobets T, Grekov I, Lipoldova M. Leishmaniasis: prevention, parasite detection and treatment. Current Medicinal Chemistry 2012;19(10): 1443-74.

[4] Welburn SC, Maudlin I. Priorities for the elimination of sleeping sickness. Advances in Parasitology 2012;79:299-337.

[5] Centers for Disease Control and Prevention. Toxoplasmosis. http://www.cdc.gov/ parasites/toxoplasmosis/ (accessed 17 october 2012).

[6] World Health Organization. Working to overcome the global impact of neglected tropical diseases - First WHO report on neglected tropical diseases. Switzerland. 2010. 
[7] Bañuls AL, Hide M, Prugnolle F. Leishmania and the leishmaniases: a parasite genetic update and advances in taxonomy, epidemiology and pathogenicity in humans. Advances in Parasitology 2007;64:1-109.

[8] Stuart K, Brun R, Croft S, Fairlamb A, Gürtler RE, McKerrow J, et al. Kinetoplastids: related protozoan pathogens, different diseases. The Journal of Clinical Investigation 2008;118(4): 1301-10.

[9] Greenwood BM, Fidock DA, Kyle DE, Kappe SH, Alonso PL, Collins FH, et al. Malaria: progress, perils, and prospects for eradication. Journal of Clinical Investigation 2008;118(4): 1266-76.

[10] Boyle JP, Radke JR. A history of studies that examine the interactions of Toxoplasma with its host cell: Emphasis on in vitro models. International Journal of Parasitology 2009;39(8): 903-14.

[11] Teixeira AR, Gomes C, Lozzi SP, Hecht MM, Rosa AeC, Monteiro PS, et al. Environment, interactions between Trypanosoma cruzi and its host, and health. Cadernos de Saúde Pública 2009;25 (1): S32-44.

[12] Nwaka S, Hudson A. Innovative lead discovery strategies for tropical diseases. Nature Reviews Drug Discovery 2006;5(11): 941-55.

[13] Hotez PJ, Bottazzi ME, Franco-Paredes C, Ault SK, Periago MR. The neglected tropical diseases of Latin America and the Caribbean: a review of disease burden and distribution and a roadmap for control and elimination. PLoS Neglected Tropical Diseases 2008;2(9):e300.

[14] Le Pape P. Development of new antileishmanial drugs--current knowledge and future prospects. Journal of Enzyme Inhibition and Medicinal Chemistry 2008;23(5): 708-18.

[15] Nissapatorn V, Sawangjaroen N. Parasitic infections in HIV infected individuals: diagnostic \& therapeutic challenges. The Indian Journal of Medical Research 2011;134(6): 878-97.

[16] Hotez PJ, Savioli L, Fenwick A. Neglected tropical diseases of the Middle East and North Africa: review of their prevalence, distribution, and opportunities for control. PLoS Neglected Tropical Diseases 2012;6(2):e1475.

[17] Lindoso JA, Lindoso AA. Neglected tropical diseases in Brazil. Revista do Instituto de Medicina Tropical de São Paulo 2009;51(5): 247-53.

[18] Feasey N, Wansbrough-Jones M, Mabey DC, Solomon AW. Neglected tropical diseases. British Medical Bulletin 2010;93: 179-200.

[19] World Health Organization. http://www.who.int/neglected_diseases/en/ access in November 8, 2012.

[20] Montoya JG, Liesenfeld, O. Toxoplasmosis. Lancet 2004;363(9425): 1965-76. 
[21] Kiel JAKW. Autophagy in unicellular eukaryotes. Philosophical Transactions of the Royal Society 2010;365: 819-830.

[22] Brennand A, Gualdrón-López M, Coppens I, Rigden DJ, Ginger ML, Michels PAM. Autophagy in parasitic protists: Unique features and drug targets. Molecular and Biochemical Parasitology 2011;177 (2): 83-99.

[23] Levine B, Yuan J. Autophagy in cell death: an innocent convict? Clinical Investigation 2005;115(10):2679-88.

[24] Mitzushima N, Yoshimori T, Ohsumi Y. The role of Atg proteins in autophagosome formation. Annual Review of Cell Developmental Biology 2011; 27: 107-32.

[25] Levine B, Mizushima N, Virgin HW. Autophagy in immunity and inflammation. Nature 2011;469(7330): 323-35.

[26] Sumpter R, Levine B. Autophagy and innate immunity: triggering, targeting and tuning. Seminars in Cell \& Developmental Biology 2010;21(7): 699-711.

[27] Kuballa P, Nolte WM, Castoreno AB, Xavier RJ. Autophagy and the immune system. Annual Review of Immunology 2012;30: 611-46.

[28] Gutierrez MG, Master SS, Singh SB, Taylor GA, Colombo MI, Deretic V. Autophagy is a defense mechanism inhibiting BCG and Mycobacterium tuberculosis survival in infected macrophages. Cell. 2004;119(6): 753-66.

[29] Deretic V, Levine B. Autophagy, immunity, and microbial adaptations. Cell Host \& Microbe 2009;5(6): 527-49.

[30] Skendros P, Mitroulis I. Host cell autophagy in immune response to zoonotic infections. Clinical \& Development Immunology 2012;2012: 91052. doi: 10.1155/2012/910525. (accessed 17 October 2012).

[31] Picazarri K, Nakada-Tsukui K, Nozaki T. Autophagy during proliferation and encystation in the protozoan parasite Entamoeba invadens. Infection \& Immunity. 2008;76(1): 278-88.

[32] Zhao Z, Fux B, Goodwin M, Dunay IR, Strong D, Miller BC, et al. Autophagosomeindependent essential function for the autophagy protein Atg5 in cellular immunity to intracellular pathogens. Cell host and Microbe 2008;4(5): 458-69.

[33] Pinheiro RO, Nunes MP, Pinheiro CS, D'Avila H, Bozza PT, Takiya CM, et al. Induction of autophagy correlates with increased parasite load of Leishmania amazonensis in BALB/c but not C57BL/6 macrophages. Microbes and Infection 2009;11(2): 181-90.

[34] Romano PS, Arboit MA, Vázquez CL, Colombo MI. The autophagic pathway is a key component in the lysosomal dependent entry of Trypanosoma cruzi into the host cell. Autophagy 2009;5(1): 6-18. 
[35] Wang Y, Weiss LM, Orlofsky A. Host cell autophagy is induced by Toxoplasma gondii and contributes to parasite growth. The Journal of biological chemistry 2009;284(3): 1694-1701.

[36] Duszenko M, Ginger ML, Brennand A, Gualdrón-López M, Colombo MI, et al. Autophagy in protists. Autophagy. 2011;7(2): 127-58.

[37] Alvarez VE, Kosec G, Sant'Anna C, Turk V, Cazzulo JJ, Turk B. Autophagy is involved in nutritional stress response and differentiation in Trypanosoma cruzi. The Journal of Biological Chemistry. 2008; 283(6): 3454-64.

[38] Besteiro S, Williams RA, Morrison LS, Coombs GH, Mottram JC. Endosome sorting and autophagy are essential for differentiation and virulence of Leishmania major. The Journal of Biological Chemistry 2006;281(16): 11384-96.

[39] Saraiva EM, Pimenta PF, Brodin TN, Rowton E, Modi GB, Sacks DL. Changes in lipophosphoglycan and gene expression associated with the development of Leishmania major in Phlebotomus papatasi. Parasitology. 1995;111 (Pt 3): 275-87.

[40] Nolan DP, Rolin S, Rodriguez JR, Van Den Abbeele J, Pays E. Slender and stumpy bloodstream forms of Trypanosoma brucei display a differential response to extracellular acidic and proteolytic stress. European Journal of Biochemistry 2000;267(1): 18-27

[41] Gonçalves RL, Barreto RF, Polycarpo CR, Gadelha FR, Castro SL, Oliveira MF. A comparative assessment of mitochondrial function in epimastigotes and bloodstream trypomastigotes of Trypanosoma cruzi. Journal of Bioenergetics and Biomembranes 2011;43(6): 651-61.

[42] Castro DP, Moraes CS, Gonzalez MS, Ratcliffe NA, Azambuja P, Garcia ES. Trypanosoma cruzi immune response modulation decreases microbiota in Rhodnius prolixus gut and is crucial for parasite survival and development. PLoS One. 2012;7(5):e36591.

[43] Berriman M, Ghedin E, Hertz-Fowler C, Blandin G, Renauld H, Bartholomeu DC, et al. The genome of the African trypanosome Trypanosoma brucei. Science 2005;309(5733): 416-22.

[44] El-Sayed NM, Myler PJ, Bartholomeu DC, Nilsson D, Aggarwal G, Tran AN, et al. The genome sequence of Trypanosoma cruzi, etiologic agent of Chagas disease. Science 2005;309(5733): 409-15.

[45] Ivens AC, Peacock CS, Worthey EA, Murphy L, Aggarwal G, Berriman M, et al. The genome of the kinetoplastid parasite, Leishmania major. Science 2005;309(5733): 436-42.

[46] Rigden DJ, Herman M, Gillies S, Michels PA. Implications of a genomic search for autophagy-related genes in trypanosomatids. Biochemical Society Transactions 2005;33(Pt 5): 972-4. 
[47] Herman M, Gillies S, Michels PA, Rigden DJ. Autophagy and related processes in trypanosomatids: insights from genomic and bioinformatic analyses. Autophagy 2006;2(2): 107-18.

[48] Hidron A, Vogenthaler N, Santos-Preciado JI, Rodriguez-Morales AJ, Franco-Paredes C, Rassi A. Cardiac involvement with parasitic infections. Clinical Microbiology Reviews 2010;23(2): 324-49.

[49] Brown RC, Evans DA, Vickerman K. Developmental changes in ultrastructure and physiology of Trypanosoma brucei. Transactions of Royal Society of Tropical Medicine Hygiene 1972;66(2): 336-7.

[50] Vickerman K, Tetley L. Recent ultrastructural studies on trypanosomes. Annales de la Société Belge de Médecine Tropicale 1977;57(4-5): 441-57.

[51] Herman M, Pérez-Morga D, Schtickzelle N, Michels PA. Turnover of glycosomes during life-cycle differentiation of Trypanosoma brucei. Autophagy 2008;4(3): 294-308.

[52] Barquilla A, Crespo JL, Navarro M. Rapamycin inhibits trypanosome cell growth by preventing TOR complex 2 formation. Proceedings of National Academy of Sciences U S A 2008;105(38): 14579-84.

[53] Koopmann R, Muhammad K, Perbandt M, Betzel C, Duszenko M. Trypanosoma brucei ATG8: structural insights into autophagic-like mechanisms in protozoa. Autophagy 2009;5(8): 1085-91.

[54] Li FJ, Shen Q, Wang C, Sun Y, Yuan AY, He CY. A role of autophagy in Trypanosoma brucei cell death. Cellular Microbiology 2012;14(8): 1242-56.

[55] Uzcátegui NL, Carmona-Gutiérrez D, Denninger V, Schoenfeld C, Lang F, Figarella $\mathrm{K}$, et al. Antiproliferative effect of dihydroxyacetone on Trypanosoma brucei bloodstream forms: cell cycle progression, subcellular alterations, and cell death. Antimicrobial Agents and Chemotherapy 2007;51(11): 3960-8.

[56] Uzcátegui NL, Denninger V, Merkel P, Schoenfeld C, Figarella K, Duszenko M. Dihydroxyacetone induced autophagy in African trypanosomes. Autophagy 2007;3(6): 626-9.

[57] Merkel P, Beck A, Muhammad K, Ali SA, Schönfeld C, Voelter W, et al. Spermine isolated and identified as the major trypanocidal compound from the snake venom of Eristocophis macmahoni causes autophagy in Trypanosoma brucei. Toxicon 2007;50(4): 457-69.

[58] Delgado M, Anderson P, Garcia-Salcedo JA, Caro M, Gonzalez-Rey E. Neuropeptides kill African trypanosomes by targeting intracellular compartments and inducing autophagic-like cell death. Cell Death and Differetiation 2009;16(3): 406-16. 
[59] Denninger V, Koopmann R, Muhammad K, Barth T, Bassarak B, Schönfeld C, et al. Kinetoplastida: model organisms for simple autophagic pathways? Methods in Enzymology 2008;451: 373-408.

[60] Zhang Y, Qi H, Taylor R, Xu W, Liu LF, Jin S. The role of autophagy in mitochondria maintenance: characterization of mitochondrial functions in autophagy-deficient $S$. cerevisiae strains. Autophagy 2007;3(4): 337-46.

[61] Chen $Y$, Gibson SB. Is mitochondrial generation of reactive oxygen species a trigger for autophagy? Autophagy 2008;4(2): 246-8.

[62] Scherz-Shouval R, Elazar Z. Regulation of autophagy by ROS: physiology and pathology. Trends in BiochemicalSciences 2011;36(1): 30-8.

[63] Braga MV, Magaraci F, Lorente SO, Gilbert I, de Souza W. Effects of inhibitors of Delta24(25)-sterol methyl transferase on the ultrastructure of epimastigotes of Trypanosoma cruzi. Microscopy and Microanalysis 2005;11(6): 506-15.

[64] Santa-Rita RM, Lira R, Barbosa HS, Urbina JA, de Castro SL. Anti-proliferative synergy of lysophospholipid analogues and ketoconazole against Trypanosoma cruzi (Kinetoplastida: Trypanosomatidae): cellular and ultrastructural analysis. The Journal of Antimicrobial Chemotherapy 2005;55(5): 780-4.

[65] Menna-Barreto RF, Corrêa JR, Pinto AV, Soares MJ, de Castro SL. Mitochondrial disruption and DNA fragmentation in Trypanosoma cruzi induced by naphthoimidazoles synthesized from beta-lapachone. Parasitology Research 2007;101(4): 895-905.

[66] Menna-Barreto RF, Corrêa JR, Cascabulho CM, Fernandes MC, Pinto AV, Soares MJ, et al. Naphthoimidazoles promote different death phenotypes in Trypanosoma cruzi. Parasitology 2009;136(5): 499-510.

[67] Fernandes MC, Da Silva EN, Pinto AV, De Castro SL, Menna-Barreto RF. A novel triazolic naphthofuranquinone induces autophagy in reservosomes and impairment of mitosis in Trypanosoma cruzi. Parasitology 2012;139(1): 26-36.

[68] Veiga-Santos P, Barrias ES, Santos JF, de Barros Moreira TL, de Carvalho TM, Urbina JA, et al. Effects of amiodarone and posaconazole on the growth and ultrastructure of Trypanosoma cruzi. International Journal of Antimicrobial Agents 2012;40(1): 61-71.

[69] Menna-Barreto RF, Salomão K, Dantas AP, Santa-Rita RM, Soares MJ, Barbosa HS, et al. Different cell death pathways induced by drugs in Trypanosoma cruzi: an ultrastructural study. Micron 2009;40(2): 157-68.

[70] DaRocha WD, Otsu K, Teixeira SM, Donelson JE. Tests of cytoplasmic RNA interference (RNAi) and construction of a tetracycline-inducible T7 promoter system in Trypanosoma cruzi. Molecular and Biochemical Parasitolology 2004;133(2): 175-86.

[71] Sandes JM, Borges AR, Junior CG, Silva FP, Carvalho GA, Rocha GB, et al. 3-Hydroxy-2-methylene-3-(4-nitrophenylpropanenitrile): A new highly active compound 
against epimastigote and trypomastigote form of Trypanosoma cruzi. Bioorganic Chemistry 2010;38(5): 190-5.

[72] Benitez D, Pezaroglo H, Martínez V, Casanova G, Cabrera G, Galanti N, et al. Study of Trypanosoma cruzi epimastigote cell death by NMR-visible mobile lipid analysis. Parasitology 2012 139(4): 506-15.

[73] Soares MJ, Souto-Padrón T, De Souza W. Identification of a large pre-lysosomal compartment in the pathogenic protozoon Trypanosoma cruzi. Journal of Cell Science 1992;102 (Pt 1): 157-67.

[74] Soares MJ. The reservosome of Trypanosoma cruzi epimastigotes: an organelle of the endocytic pathway with a role on metacyclogenesis. Memórias do Instituto Oswaldo Cruz 1999;94 (1): 139-41.

[75] Figueiredo RC, Rosa DS, Soares MJ. Differentiation of Trypanosoma cruzi epimastigotes: metacyclogenesis and adhesion to substrate are triggered by nutritional stress. The Journal of Parasitology 2000;86(6): 1213-8.

[76] Alvarez VE, Kosec G, Sant Anna C, Turk V, Cazzulo JJ, Turk B. Blocking autophagy to prevent parasite differentiation: a possible new strategy for fighting parasitic infections? Autophagy 2008;4(3): 361-3

[77] Braga MV, de Souza W. Effects of protein kinase and phosphatidylinositol-3 kinase inhibitors on growth and ultrastructure of Trypanosoma cruzi. FEMS Microbiology Letters 2006;256(2): 209-16.

[78] Petiot A, Ogier-Denis E, Blommaart EF, Meijer AJ, Codogno P. Distinct classes of phosphatidylinositol 3'-kinases are involved in signaling pathways that control macroautophagy in HT-29 cells. The Journal of Biological Chemistry. 2000; 275(2): 992-8.

[79] Romano PS, Cueto JA, Casassa AF, Vanrell MC, Gottlieb RA, Colombo MI. Molecular and cellular mechanisms involved in the Trypanosoma cruzi/host cell interplay. IUBMB Life 2012;64(5): 387-96.

[80] Martins RM, Alves RM, Macedo S, Yoshida N. Starvation and rapamycin differentially regulate host cell lysosome exocytosis and invasion by Trypanosoma cruzi metacyclic forms. Cellular Microbiology 2011;13(7): 943-54.

[81] Maeda FY, Alves RM, Cortez C, Lima FM, Yoshida N. Characterization of the infective properties of a new genetic group of Trypanosoma cruzi associated with bats. Acta Tropica 2011;120(3): 231-7.

[82] Bera A, Singh S, Nagaraj R, Vaidya T. Induction of autophagic cell death in Leishmania donovani by antimicrobial peptides. Molecular and Biochemichal Parasitology 2003;127(1): 23-35. 
[83] Dos Santos AO, Veiga-Santos P, Ueda-Nakamura T, Filho BP, Sudatti DB, Bianco EM, et al. Effect of elatol, isolated from red seaweed Laurencia dendroidea, on Leishmania amazonensis. Marine Drugs 2010;8(11): 2733-43.

[84] Santos AO, Santin AC, Yamaguchi MU, Cortez LE, Ueda-Nakamura T, Dias-Filho $\mathrm{BP}$, et al. Antileishmanial activity of an essential oil from the leaves and flowers of Achillea millefolium. Annals of Tropical Medicine and Parasitology 2010;104(6): 475-83.

[85] Schurigt U, Schad C, Glowa C, Baum U, Thomale K, Schnitzer JK, et al. Aziridine-2,3dicarboxylate-based cysteine cathepsin inhibitors induce cell death in Leishmania major associated with accumulation of debris in autophagy-related lysosome-like vacuoles. Antimicrobial Agents and Chemotherapy 2010;54(12): 5028-41.

[86] de Macedo-Silva ST, de Oliveira Silva TL, Urbina JA, de Souza W, Rodrigues JC. Antiproliferative, Ultrastructural, and Physiological Effects of Amiodarone on Promastigote and Amastigote Forms of Leishmania amazonensis. Molecular Biology International 2011; doi: 10.4061/2011/876021 (accessed 17 October 2012).

[87] Monte Neto RL, Sousa LM, Dias CS, Barbosa Filho JM, Oliveira MR, Figueiredo RC. Morphological and physiological changes in Leishmania promastigotes induced by yangambin, a lignan obtained from Ocotea duckei. Experimental Parasitology 2011;127(1):215-21.

[88] Sengupta S, Chowdhury S, Bosedasgupta S, Wright CW, Majumder HK. Cryptolepine-Induced Cell Death of Leishmania donovani Promastigotes Is Augmented by Inhibition of Autophagy. Molecular Biological International 2011;2011: 187850.

[89] Silva AL, Adade CM, Shoyama FM, Neto CP, Padrón TS, de Almeida MV, et al. In vitro leishmanicidal activity of N-dodecyl-1,2-ethanediamine. Biomedicine and Pharmacotherapy 2012;66(3): 180-6.

[90] Williams RA, Tetley L, Mottram JC, Coombs GH. Cysteine peptidases CPA and CPB are vital for autophagy and differentiation in Leishmania mexicana. Molecular Microbiology 2006;61(3): 655-74.

[91] ] Besteiro S, Williams RA, Coombs GH, Mottram JC. Protein turnover and differentiation in Leishmania. International Journal for Parasitology 2007;37(10): 1063-75.

[92] Bhattacharya A, Biswas A, Das PK. Identification of a protein kinase A regulatory subunit from Leishmania having importance in metacyclogenesis through induction of autophagy. Molecular Microbiology 2012;83(3): 548-64.

[93] Williams RAM, Woods KL, Juliano L, Mottram JC, Coombs GH. Characterisation of unusual families of ATG8-like proteins and ATG12 in the protozoan parasite Leishmania major. Autophagy 2009;5(2): 159-172.

[94] Williams RAM, Smith TK, Cull B, Mottram JC, Coombs GH. ATG5 is Essential for ATG8-Dependent Autophagy and Mitochondrial Homeostasis in Leishmania major. Plos Pathogens 2012; 8 (5): 1-14. 
[95] Goldshmidt H, Matas D, Kabi A, Carmi S, Hope R, Michaeli S. Persistent ER stress induces the spliced leader RNA silencing pathway (SLS), leading to programmed cell death in Trypanosoma brucei. PLoS Pathogens 2010;6(1):e1000731.

[96] Schaible UE, Schlesinger PH, Steinberg TH, Mangel WF, Kobayashi T, Russell DG. Parasitophorous vacuoles of Leishmania mexicana acquire macromolecules from the host cell cytosol via two independent routes. Journal of Cell Science 1999;112( Pt 5): 681-93.

[97] Cyrino LT, Araújo AP, Joazeiro PP, Vicente CP, Giorgio S. In vivo and in vitro Leishmania amazonensis infection induces autophagy in macrophages. Tissue \& Cell 2012; doi: http://dx.doi.org/10.1016/j.tice.2012.08.003 (accessed 17 October 2012).

[98] Mitroulis I, Kourtzelis I, Papadopoulos VP, Mimidis K, Speletas M, Ritis K. In vivo induction of the autophagic machinery in human bone marrow cells during Leishmania donovani complex infection. Parasitology International 2009;58(4):475-7.

[99] Besteiro S. Which roles for autophagy in Toxoplasma gondii and related apicomplexan parasites? Molecular and Biochemical Parasitology 2012;184: 1-8.

[100] Xie Z, Nair U, Klionsky DJ. Atg8 controls phagophore expansion during autophagosome formation. Molecular biology of the cell 2008;19(8): 3290-8.

[101] Shvets E, Fass E, Scherz-Shouval R, Elazar Z. The N-terminus and Phe52 residue of LC3 recruit p62/SQSTM1 into autophagosomes. Journal of cell science 2008;121(Pt 16): 2685-95.

[102] Besteiro S, Brooks CF, Striepen B, Dubremetz JF. Autophagy protein Atg3 is essential for maintaining mitochondrial integrity and for normal intracellular development of Toxoplasma gondii tachyzoites. PLoS pathogens 2011;7(12): e1002416.

[103] Diaz-Troya S, Perez-Perez ME, Florencio FJ, Crespo JL. The role of TOR in autophagy regulation from yeast to plants and mammals. Autophagy 2008;4(7): 851-65.

[104] Rigden DJ, Michels PA, Ginger ML. Autophagy in protists: Examples of secondary loss, lineage-specific innovations, and the conundrum of remodeling a single mitochondrion. Autophagy 2009;5(6): 784-94.

[105] Dubey JP, Jones JL. Toxoplasma gondii infection in humans and animals in the United States. International journal for parasitology 2008;38(11): 1257-78.

[106] Furtado JM, Smith JR, Belfort R Jr., Gattey D, Winthrop KL. Toxoplasmosis: a global threat. Journal of global infectious diseases 2011;3(3): 281-4.

[107] Mordue DG, Hakansson S, Niesman I, Sibley, LD. Toxoplasma gondii resides in a vacuole that avoids fusion with host cell endocytic and exocytic vesicular trafficking pathways. Experimental parasitology 1999;92(2): 87-99.

[108] Sullivan WJ Jr., Jeffers V. Mechanisms of Toxoplasma gondii persistence and latency. FEMS microbiology reviews 2012;36(3): 717-33. 
[109] Ambroise-Thomas P, Pelloux H. Toxoplasmosis - congenital and in immunocompromised patients: a parallel. Parasitology today 1993;9(2): 61-3.

[110] Mele A, Paterson PJ, Prentice HG., Leoni P, Kibbler CC. Toxoplasmosis in bone marrow transplantation: a report of two cases and systematic review of the literature. Bone marrow transplantation 2002;29(8): 691-8.

[111] Innes EA. A brief history and overview of Toxoplasma gondii. Zoonoses and public health 2010;57(1): 1-7.

[112] Ghosh D, Walton JL, Roepe PD, Sinai AP. Autophagy is a cell death mechanism in Toxoplasma gondii. Cellular microbiology 2012;14(4): 589-607.

[113] Besteiro S. Role of ATG3 in the parasite Toxoplasma gondii: Autophagy in an early branching eukaryote. Autophagy 2012;8(3): 435-7.

[114] Youle RJ, Narendra DP. Mechanisms of mitophagy. Nature reviews Molecular cell biology 2011;12(1): 9-14.

[115] Meijer AJ, Codogno P. Regulation and role of autophagy in mammalian cells. The international journal of biochemistry and cell biology 2004;36(12): 2445-62.

[116] Dubey JP, Frenkel JK. Cyst-induced toxoplasmosis in cats. The Journal of protozoology 1972;19(1): 155-7.

[117] Dubey JP, Frenkel JK. Experimental toxoplasma infection in mice with strains producing oocysts. The Journal of parasitology 1973; 59(3): 505-12.

[118] Dubey JP. Feline toxoplasmosis and coccidiosis: a survey of domiciled and stray cats. Journal of the American Veterinary Medical Association 1973; 162(10): 873-7.

[119] Denton D, Nicolson S, Kumar S. Cell death by autophagy: facts and apparent artefacts. Cell death and differentiation 2012;19(1): 87-95.

[120] Yahiaoui B, Dzierszinski F, Bernigaud A, Slomianny C, Camus D, Tomavo S. Isolation and characterization of a subtractive library enriched for developmentally regulated transcripts expressed during encystation of Toxoplasma gondii. Molecular and biochemical parasitology 1999;99(2): 223-35.

[121] Pfefferkorn ER. Interferon gamma blocks the growth of Toxoplasma gondii in human fibroblasts by inducing the host cells to degrade tryptophan. Proceedings of the National Academy of Sciences of the United States of America 1984;81(3): 908-12.

[122] Pfefferkorn ER, Eckel M, Rebhun S. Interferon-gamma suppresses the growth of Toxoplasma gondii in human fibroblasts through starvation for tryptophan. Molecular and biochemical parasitology 1986;20(3): 215-24.

[123] Black MW, Boothroyd JC. Lytic cycle of Toxoplasma gondii. Microbiology and molecular biology reviews 2000;64(3): 607-23.

[124] Andrade RM, Wessendarp M, Gubbels MJ, Striepen B, Subauste, CS. CD40 induces macrophage anti-Toxoplasma gondii activity by triggering autophagy-dependent fu- 
sion of pathogen-containing vacuoles and lysosomes. The Journal of clinical investigation 2006;116(9): 2366-77.

[125] Ling Y M, Shaw MH, Ayala C, Coppens I, Taylor GA, Ferguson DJ, et al.. Vacuolar and plasma membrane stripping and autophagic elimination of Toxoplasma gondii in primed effector macrophages. The Journal of experimental medicine 2006;203(9): 2063-271.

[126] Subauste CS, Andrade RM, Wessendarp M. CD40-TRAF6 and autophagy-dependent anti-microbial activity in macrophages. Autophagy 2007;3(3): 245-8.

[127] Zhao Y, Wilson D, Matthews S, Yap GS. Rapid elimination of Toxoplasma gondii by gamma interferon-primed mouse macrophages is independent of CD40 signaling. Infection and immunity 2007;75(10): 4799-803.

[128] Portillo JA, Okenka G, Reed E, Subauste A, Van Grol J, Gentil K, et al. The CD40-autophagy pathway is needed for host protection despite IFN-Gamma-dependent immunity and CD40 induces autophagy via control of P21 levels. PLoS One 2010;5(12): e14472.

[129] Bogdan C, Rollinghoff M. How do protozoan parasites survive inside macrophages? Parasitology Today 1999;15(1): 22-8.

[130] Halonen SK. Role of autophagy in the host defense against Toxoplasma gondii in astrocytes. Autophagy 2009;5(2): 268-9.

[131] Cox-Singh J, Davis TM, Lee KS, Shamsul SS, Matusop A, Ratnam S, et al. Plasmodium knowlesi malaria in humans is widely distributed and potentially life threatening. Clinical infectious diseases 2008;46(2): 165-71.

[132] Marchand RP, Culleton R, Maeno Y, Quang NT, Nakazawa S. Co-infections of Plasmodium knowlesi, P. falciparum, and P. vivax among Humans and Anopheles dirus Mosquitoes, Southern Vietnam. Emerging infectious diseases 2011;17(7): 1232-9.

[133] William T, Menon J, Rajahram G, Chan L, Ma G, Donaldson S, et al. Severe Plasmodium knowlesi malaria in a tertiary care hospital, Sabah, Malaysia. Emerging infectious diseases 2011;17(7): 1248-55.

[134] Frevert U, Engelmann S, Zougbede S, Stange J, Ng B, Matuschewski K, et al. Intravital observation of Plasmodium berghei sporozoite infection of the liver. PLoS biology 2005;3(6): e192.

[135] Amino R, Thiberge S, Martin B, Celli S, Shorte S, Frischknecht F, et al. Quantitative imaging of Plasmodium transmission from mosquito to mammal. Nature Medicine 2006;12(2): 220-4.

[136] Sturm A, Amino R, van de Sand C, Regen T, Retzlaff S, Rennenberg A, et al. Manipulation of host hepatocytes by the malaria parasite for delivery into liver sinusoids. Science 2006;313(5791): 1287-90. 
[137] Jayabalasingham B, Bano N, Coppens I. Metamorphosis of the malaria parasite in the liver is associated with organelle clearance. Cell Research 2010; 20: 1043-1059.

[138] Coppens I. Metamorphoses of malaria: the role of autophagy in parasite differentiation. Essays in biochemistry 2011;51: 127-36.

[139] Vaid A, Ranjan R, Smythe WA, Hoppe HC, Sharma P. PfPI3K, a phosphatidylinositol-3 kinase from Plasmodium falciparum, is exported to the host erythrocyte and is involved in hemoglobin trafficking. Blood 2010;115(12): 2500-7.

[140] Kitamura K, Kishi-Itakura C, Tsuboi T, Sato S, Kita K, Ohta N, Mizushima N. Autophagy-Related Atg8 Localizes to the Apicoplast of the Human Malaria Parasite Plasmodium falciparum. Plos one 2012;7(8): 1-10. 
